\title{
THERMAL BEHAVIOUR OF DIFFERENT TYPES OF COMMERCIAL COFFEE AND RESULTING COFFEE GROUNDS IN INERT ATMOSPHERE. THE INFLUENCE OF COMPOSITION
}

\author{
(ARABICA AND ROBUSTA)
}

\author{
VICTORIA BEJENARI and GABRIELA LISA \\ "Gheorghe Asachi” Technical University, "Cristofor Simionescu” Faculty of Chemical Engineering and \\ Environmental Protection, Department of Chemical Engineering, Iaşi, Romania \\ $\bowtie$ Corresponding author: Gabriela Lisa, gapreot@yahoo.com
}

Dedicated to the Department of Pulp and Paper

on the occasion of its $70^{\text {th }}$ anniversary

\begin{abstract}
This paper aims at analysing the thermal behaviour of six types of commercial coffee and the coffee grounds resulting from their use in a professional DeLonghi coffee machine. The influence of composition (Arabica and Robusta) on the thermal behaviour was thus highlighted for the first time. The obtained results indicate that the degradation occurs in three or four stages, based on the composition. The first stage consists in water removal, which can be found in a percentage of 1 up to $5 \%$. The thermal decomposition of the samples starts at temperatures higher than $230{ }^{\circ} \mathrm{C}$, in the case of both, different coffee types and coffee grounds. By comparatively analysing the temperature values at which the degradation starts, it can be noticed that in all the cases there is an increase in the thermal stability of the coffee grounds with approximately 20 degrees, compared to the coffee types they come from. For coffee grounds originating from coffee that contains 35\% Arabica and 65\% Robusta, the degradation mechanisms change at temperatures higher than $320^{\circ} \mathrm{C}$, as confirmed by the occurrence of an additional degradation stage, compared to the case of other samples. The obtained DSC curves emphasized the presence of two melting peaks and one crystallization peak, which, according to the specialty literature, indicates the presence of coffee oil.
\end{abstract}

Keywords: thermal behaviour, commercial coffee, coffee grounds, TG, DTG, DSC

\section{INTRODUCTION}

The increase of the purchasing power and certain tax reliefs, namely, the excise duty relief from 2016, contributed to a significant growth in coffee consumption in Romania in recent years. Following the growth in coffee consumption, there results an increasing amount of coffee grounds, which could be exploited. ${ }^{1,2}$

The coffee shrub belongs to the Coffea genus, which includes many species. The coffee shrub produces fleshy fruits, a kind of cherries. Each fruit has two seeds inside, known as coffee beans. These seeds are separated from the fleshy covering, dried, fried, mixed, ground and finally cooked in the form of coffee in various specialties.
The quality of the coffee is determined by the variety used, by the crop and harvesting system, by the roasting and grinding processes, as well as by the dosage of the mixture.

The main types of coffee are:

- Arabica, which is a superior coffee species, with high content of oils and sugars, and lower caffeine content than Robusta. Arabic coffee varieties can have a wide range of flavours (slightly fruity, caramel, nuts, honey, chocolate, etc.), depending on the origin of the coffee plant. $100 \%$ Arabica certified coffee is the purest, most refined and tasty coffee recommended for consumption.

- Robusta, which is an inferior coffee species, usually grown and used in lower coffee 
mixes. It is a bitter coffee with high caffeine content, but without the flavour and savour of Arabica varieties. Usually, Robusta is added in blends with Arabica, for economic reasons (coffee at a lower price). In traditional Italian recipes of espresso (especially miscella napoletana), Robusta is added at a minimum of $20 \%$ to the Arabica content to increase the caffeine content of the coffee. $100 \%$ Robusta coffee is not recommended for consumption, although it is still commercially available on the Romanian market, especially in coffee bean mixes for vending machines.

Coffee is undoubtedly the most common and most popular drink in the world. People around the world have been serving coffee for over 400 years, prepared in one way or another. Not a day goes by without the majority of the inhabitants of this planet bringing to the lips a steaming cup of coffee (400 billion cups of coffee are served each year worldwide).

The trade and consumption of coffee throughout the world is steadily increasing, generating enormous quantities of solid residue, called coffee grounds. In recent years, coffee grounds have attracted the attention of many researchers as a promising material for various processes and for making it worthwhile in high value products. ${ }^{3}$ Thus, this solid residue started to be seen as a material with enormous potential for various applications, having the advantage of being an inexpensive and affordable material.

Ballesteros et al. have analysed the chemical composition, functional properties and structural characteristics of some agro-industrial residues, including coffee grounds, in order to identify the characteristics that allow them to be reused in industrial processes. ${ }^{4}$ They studied the thermal behaviour of coffee grounds by applying the TGA and DSC techniques in a nitrogen atmosphere at $10{ }^{\circ} \mathrm{C} / \mathrm{min}$ rate, within the $25-600{ }^{\circ} \mathrm{C}$ temperature range. They revealed the existence of three decomposition stages, of which, the second saw the highest percentage of mass loss, namely within the $300-600{ }^{\circ} \mathrm{C}$ temperature range. A. E. Atabani et al. also identified three decomposition stages of coffee grounds in nitrogen, within the 25-1300 ${ }^{\circ} \mathrm{C}$ temperature range. ${ }^{5}$ They analysed the potential use of coffee grounds as a raw material for alternative fuel in Turkey. Their study also revealed that coffee grounds contain about $13 \%$ oil. After oil extraction, the resulting residue may be used as fertilizer, as raw material for ethanol, for biogas production, or for its processing into pellets to be used as fuel. V. M. Medina et al. identified other uses for the residues resulting from the coffee industry. ${ }^{6}$ They demonstrated the use of these residues in obtaining composite materials with applications in removing rhodamine $\mathrm{B}$ dye from aqueous solutions. They also included in their study the analysis of the thermal behaviour of coffee residues within the $25-800{ }^{\circ} \mathrm{C}$ temperature range. They identified three stages of decomposition, with $\mathrm{T}_{\text {peak }}=307{ }^{\circ} \mathrm{C}$ for the main stage, in which polysaccharide depolymerization and decomposition occur.

In this paper, we used thermogravimetric analysis and differential calorimetry to study the thermal behaviour of six types of commercial coffee and coffee grounds resulting from their use in a DeLonghi coffee machine. The analysed coffee contains different proportions of Arabica $\left(\mathrm{W}_{\mathrm{A}} \%\right)$ and Robusta $\left(\mathrm{W}_{\mathrm{B}} \%\right): \mathrm{W}_{\mathrm{A}} / \mathrm{W}_{\mathrm{B}}=100 / 0$, $70 / 30,50 / 50,35 / 65,20 / 80$ and $0 / 100$. Thus, for the first time, the influence of the composition (Arabica and Robusta) on the thermal behaviour was emphasized.

\section{EXPERIMENTAL}

\section{Materials, equipment and measurements}

The analysis of thermal behaviour was carried out by recording the TG, DTG and DTA curves with a Mettler 851 equipment. Tests were performed dynamically in nitrogen, at a flow rate of $20 \mathrm{~mL} / \mathrm{min}$, at a heating rate of $10{ }^{\circ} \mathrm{C} / \mathrm{min}$, in the temperature range of $25-700{ }^{\circ} \mathrm{C}$, using a sample weight of 2-6 mg. The kinetic data processing was performed by applying the Freeman-Carroll method. ${ }^{7,8}$

The DSC curves were recorded with a Mettler Toledo DSC1 in an inert atmosphere, at a heating speed of $10{ }^{\circ} \mathrm{C} / \mathrm{min}$. Scanning was carried out within the temperature range $-60-150{ }^{\circ} \mathrm{C}$, with two heating runs and one cooling run.

The materials subjected to thermogravimetric analysis consisted in six types of coffee and the coffee grounds resulting from their use in professional coffee machines. The coffee ground was dried in a Mettler Toledo HG63, at a temperature of $105{ }^{\circ} \mathrm{C}$. The codes of the samples under study and their percentage content of Arabica and Robusta coffee are shown in Table 1. 
Table 1

Codes of samples subjected to thermal analysis

\begin{tabular}{cccc}
\hline Nr. & Sample code & \%Arabica & \%Robusta \\
\hline 1 & A & 100 & 0 \\
2 & L & 70 & 30 \\
3 & GB & 50 & 50 \\
4 & P & 35 & 65 \\
5 & O & 20 & 80 \\
6 & M & 0 & 100 \\
\hline
\end{tabular}

\section{RESULTS AND DISCUSSION}

Figures 1 and 2 present comparatively the TG and DTG curves of the six types of coffee and coffee grounds that were subjected to thermogravimetric analysis. The thermogravimetric curves provide information on the thermal stability of the different types of coffee and the coffee grounds resulting from their use in professional coffee machines. The main thermogravimetric characteristics obtained from the thermogravimetric curves $\left(\mathrm{T}_{\mathrm{i}}-\right.$ the temperature at which degradation begins, $\mathrm{T}_{\mathrm{m}}-$ the temperature at which the degradation rate is maximum; $T_{f}-$ the temperature at which the degradation process is completed, $\mathrm{W}$ - the percentage loss of mass and the amount of residue) are shown in Table 2.

We note that degradation takes place in 3 or 4 steps. In the first stage, water removal occurs in a proportion of 0.9 to $4.6 \%$. Thermal decomposition of the samples begins at temperatures above 230 ${ }^{\circ} \mathrm{C}$ for both the different types of coffee and the coffee grounds. If we compare the temperature values at which degradation begins, we find in all the cases an increase in the thermal stability of the coffee grounds by about 20 degrees, compared to the coffee from which it originates. An increase of more than $40{ }^{\circ} \mathrm{C}$ occurs in the case of the coffee grounds (M) containing 100\% Robusta coffee. In the case of the coffee grounds (P) containing 35\% Arabica coffee and 65\% Robusta coffee, at temperatures above $320{ }^{\circ} \mathrm{C}$, the degradation mechanism changes, which is confirmed by the occurrence of an additional stage of degradation, compared to the other samples. This can be explained by the different polysaccharide content that may exist in the coffee grounds. Recently, Ballesterosa and collaborators ${ }^{9}$ have shown that coffee grounds contain galactose, arabinose, glucose, mannose and other polysaccharides in varying proportions.

The amount of residue resulting from the thermal decomposition of the analysed samples is between 7 and $32 \%$. The smallest amount was obtained for the coffee beans containing 100\% Arabica (A) and the highest amount for coffee containing 100\% Robusta coffee (M).

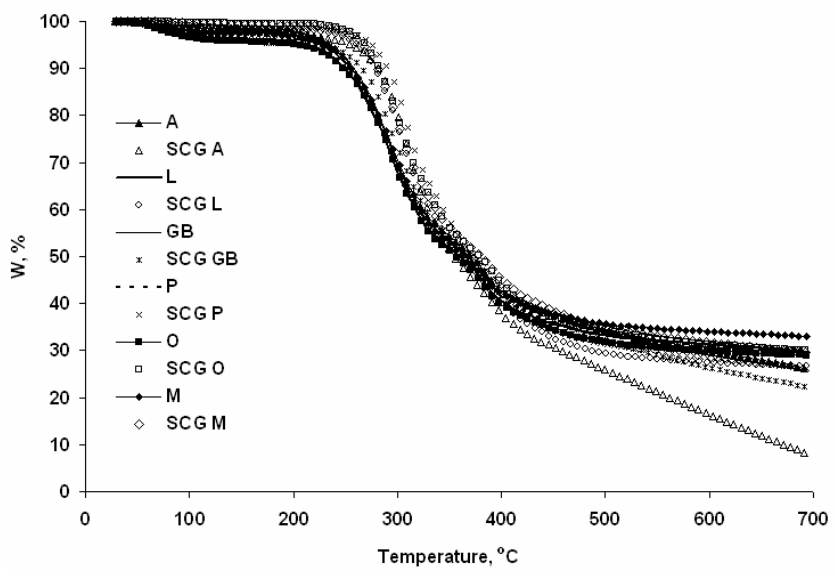

Figure 1: TG curves of different types of coffee and coffee grounds analysed 

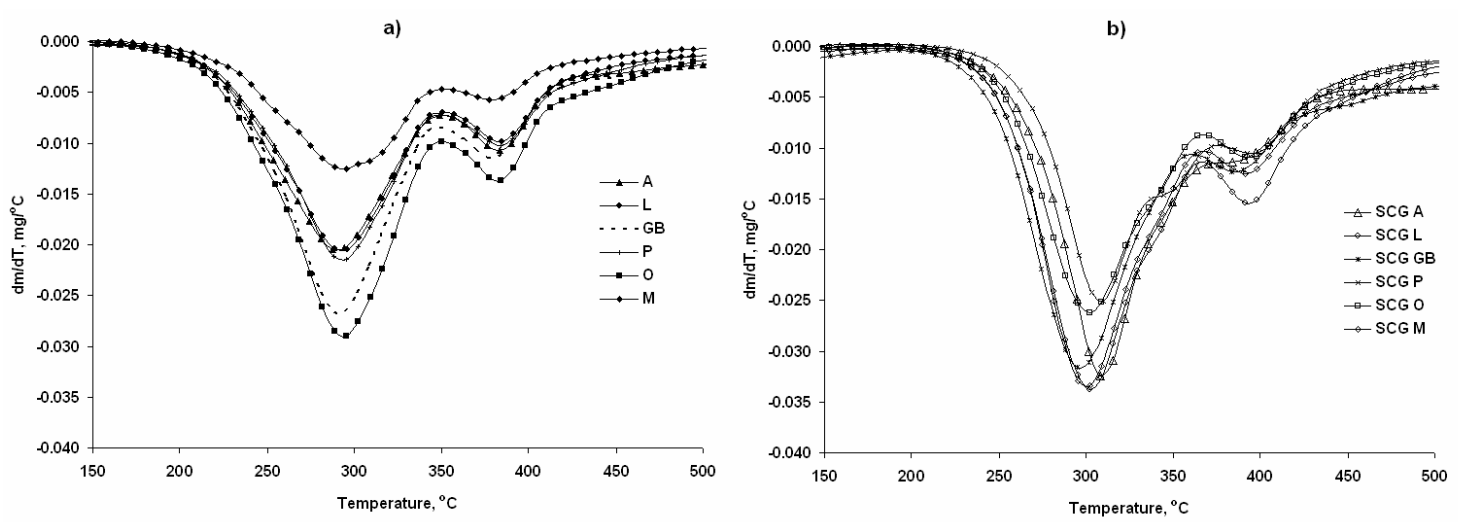

Figure 2: DTG curves for different types of coffee (a) and coffee grounds (b) analysed

The thermal behaviour of coffee grounds (collected from the University canteen) in a nitrogen atmosphere at different heating rates was analysed by Fermoso and Mašek. ${ }^{10}$ The temperature range at which the tests were performed was $25-500{ }^{\circ} \mathrm{C}$, the sample mass of about $15 \mathrm{mg}$ and one of the heating rates used was $10{ }^{\circ} \mathrm{C} / \mathrm{min}$, as in our tests. We have found that in the case of the samples analysed by us (Figs. 2a and $2 \mathrm{~b}$ ), two or three stages of decomposition are also highlighted in the temperature range of 200$500{ }^{\circ} \mathrm{C}$ and the temperature at which the degradation rate is maximum for the main stage is around $308{ }^{\circ} \mathrm{C}$, very close to that reported by Fermoso and Mašek ${ }^{10}$ in their study, and $310{ }^{\circ} \mathrm{C}$ respectively. For most of the analysed coffee ground samples, the amount of residue obtained at $700{ }^{\circ} \mathrm{C}$ is close to that reported by Fermoso and Mašek ${ }^{10}$ for the same heating speed, but at 500 ${ }^{\circ} \mathrm{C}$. A smaller amount of residue, $7.4 \%$, was obtained for the $100 \%$ Arabica coffee grounds. The three stages of decomposition obtained in the 200-500 ${ }^{\circ} \mathrm{C}$ temperature range were associated by Fermoso and Mašek ${ }^{10}$ with the decomposition of three biopolymers: hemicellulose $\left(\mathrm{T}_{\mathrm{m}}=310^{\circ} \mathrm{C}\right)$, cellulose $\left(\mathrm{T}_{\mathrm{m}}=350{ }^{\circ} \mathrm{C}\right)$ and lignin $\left(\mathrm{T}_{\mathrm{m}}=395\right.$ $\left.{ }^{\circ} \mathrm{C}\right){ }^{11-13}$ In our study, for the coffee grounds (P) containing 35\% Arabica coffee and 65\% Robusta coffee, we obtained very close values for the $T_{m}$ temperatures associated with the three steps.

The kinetic method used allows calculating the activation energy, the pre-exponential factor and the reaction order from a single TGA curve, using Equation (1) proposed by Freeman-Carroll: ${ }^{7}$

$\frac{d \alpha}{d t}=A \cdot e^{-\frac{E_{a}}{R T}}(1-\alpha)^{n}$ where $\mathrm{d} \alpha / \mathrm{dt}=$ rate of reaction in $\mathrm{s}^{-1}, \mathrm{~A}=$ preexponential factor, $\mathrm{E}_{\mathrm{a}}=$ activation energy in $\mathrm{J}$ mol $^{-1}, \mathrm{R}=$ gas constant $=8.31 \mathrm{~J} \mathrm{~mol}^{-1} \mathrm{~K}^{-1}, \mathrm{~T}=$ sample temperature in $\mathrm{K}, \alpha=$ conversion degree and $\mathrm{n}=$ order of reaction.

The kinetic parameters corresponding to the second degradation stage are presented in Table 3.

The results achieved also support the increase in the thermal stability of the coffee grounds, more precisely, the increase of the activation energy value, compared to the one recorded for the coffee type they originated from. For the different types of coffee, the activation energy is comprised between 73 and $123 \mathrm{~kJ} / \mathrm{mol}$, and for the coffee grounds it ranges between 140 and 172 $\mathrm{kJ} / \mathrm{mol}$.

The DSC curves recorded on the first heating at $10{ }^{\circ} \mathrm{C} / \mathrm{min}$ are shown in Figure 3 for the 6 types of coffee and coffee grounds. Figure 4 shows the DSC curves obtained in the cooling step.

Table 4 shows the temperatures for the melting peaks and the total melting heat expressed in $\mathrm{J} / \mathrm{g}$ for the different types of coffee and coffee grounds. Table 5 shows the crystallization peaks for the different types of coffee and coffee grounds, as well as the total heat of crystallization expressed in $\mathrm{J} / \mathrm{g}$.

According to the specialty literature, ${ }^{14,15}$ the presence of the melting peaks mentioned in Table 4 , as well as of the crystallization peaks shown in Table 5, indicates the presence of coffee oil, and moreover, they reveal that there is no significant difference in the behaviour of different types of coffee and the coffee grounds resulting from their use in professional coffee machines. Considering the findings, we consider that coffee grounds contain coffee oil that can be extracted and used for skin care cosmetics. 
Table 2

Thermogravimetric characteristics of different types of coffee and coffee grounds analysed

\begin{tabular}{|c|c|c|c|c|c|c|c|c|c|c|c|c|c|c|c|c|c|}
\hline \multirow[b]{2}{*}{$\begin{array}{l}\text { Sample } \\
\text { code }\end{array}$} & \multicolumn{4}{|c|}{ Stage 1} & \multicolumn{4}{|c|}{ Stage 2} & \multicolumn{4}{|c|}{ Stage 3} & \multicolumn{4}{|c|}{ Stage 4} & \multirow{2}{*}{$\begin{array}{c}\text { Residue } \\
(\%)\end{array}$} \\
\hline & $\begin{array}{c}\mathrm{T}_{\mathrm{i}} \\
\left({ }^{\circ} \mathrm{C}\right)\end{array}$ & $\begin{array}{c}\mathrm{T}_{\mathrm{m}} \\
\left({ }^{\circ} \mathrm{C}\right)\end{array}$ & $\begin{array}{c}\mathrm{T}_{\mathrm{f}} \\
\left({ }^{\circ} \mathrm{C}\right)\end{array}$ & $\begin{array}{c}\mathrm{W} \\
(\%)\end{array}$ & $\begin{array}{c}\mathrm{T}_{\mathrm{i}} \\
\left({ }^{\circ} \mathrm{C}\right)\end{array}$ & $\begin{array}{c}\mathrm{T}_{\mathrm{m}} \\
\left({ }^{\circ} \mathrm{C}\right)\end{array}$ & $\begin{array}{c}\mathrm{T}_{\mathrm{f}} \\
\left({ }^{\circ} \mathrm{C}\right)\end{array}$ & $\begin{array}{l}\mathrm{W} \\
(\%)\end{array}$ & $\begin{array}{c}\mathrm{T}_{\mathrm{i}} \\
\left({ }^{\circ} \mathrm{C}\right)\end{array}$ & $\begin{array}{c}\mathrm{T}_{\mathrm{m}} \\
\left({ }^{\circ} \mathrm{C}\right)\end{array}$ & $\begin{array}{c}\mathrm{T}_{\mathrm{f}} \\
\left({ }^{\circ} \mathrm{C}\right)\end{array}$ & $\begin{array}{c}\mathrm{W} \\
(\%)\end{array}$ & $\begin{array}{c}\mathrm{T}_{\mathrm{i}} \\
\left({ }^{\circ} \mathrm{C}\right)\end{array}$ & $\begin{array}{c}\mathrm{T}_{\mathrm{m}} \\
\left({ }^{\circ} \mathrm{C}\right)\end{array}$ & $\begin{array}{c}\mathrm{T}_{\mathrm{f}} \\
\left({ }^{\circ} \mathrm{C}\right)\end{array}$ & $\begin{array}{c}\mathrm{W} \\
(\%)\end{array}$ & \\
\hline A & 50.1 & 54.9 & 119.1 & 1.44 & 246.1 & 290.4 & 330.4 & 44.51 & 358.5 & 384.0 & 399.2 & 14.01 & 399.2 & 456.5 & - & 14.29 & 25.75 \\
\hline SCG A & 64.2 & 81.5 & 129.7 & 3.27 & 278.4 & 308.9 & 344.6 & 43.52 & 344.6 & 394.4 & 415.4 & 19.13 & 415.4 & 520.1 & - & 26.69 & 7.39 \\
\hline $\mathrm{L}$ & 50.7 & 68.1 & 95.53 & 3.97 & 238.4 & 292.4 & 329.3 & 44.13 & 361.1 & 384.4 & 484.8 & 22.67 & - & - & - & - & 29.22 \\
\hline SCG L & 66.5 & 78.3 & 157.6 & 1.77 & 265.1 & 302.4 & 394.8 & 46.57 & 382.2 & 394.8 & 489.7 & 25.44 & - & - & - & - & 26.20 \\
\hline GB & 43.1 & 51.6 & 112.9 & 1.78 & 248.4 & 291.2 & 327.1 & 44.26 & 356.0 & 380.9 & 397.8 & 13.96 & 397.8 & 454.2 & - & 10.85 & 29.15 \\
\hline SCG GB & 47.1 & 78.2 & 147.6 & 4.54 & 266.6 & 297.0 & 335.2 & 42.29 & 369.3 & 386.9 & 407.1 & 14.59 & 407.1 & 450.8 & - & 16.73 & 21.85 \\
\hline $\mathrm{P}$ & 45.1 & 63.9 & 139.8 & 3.13 & 245.5 & 292.6 & 330.4 & 44.74 & 375.4 & 384.5 & 494 & 22.39 & - & - & - & - & 29.74 \\
\hline SCG P & 50.4 & 75.4 & 125.2 & 1.57 & 267.6 & 308.2 & 322.3 & 31.07 & 322.3 & 344.9 & 357.5 & 14.61 & 357.5 & 397.7 & 424.5 & 27.58 & 25.17 \\
\hline $\mathrm{O}$ & 50.0 & 71.1 & 109.2 & 4.24 & 242.5 & 293.3 & 329.5 & 43.87 & 361 & 283.3 & 482.1 & 23.25 & - & - & - & - & 28.64 \\
\hline SCG O & 49.4 & 79.4 & 123.4 & 0.41 & 264.3 & 301.8 & 348.7 & 48.32 & 382.7 & 396.2 & 454.7 & 21.98 & - & - & - & - & 29.29 \\
\hline $\mathrm{M}$ & 49.6 & 64.5 & 90.7 & 2.63 & 230.6 & 296.6 & 323.2 & 43.85 & 358 & 381.1 & 446.9 & 21.33 & - & - & - & - & 32.19 \\
\hline SCG M & 67. & 79.6 & 126.8 & 0.90 & 262.1 & 299.7 & 347.1 & 46.02 & 378.5 & 393.4 & 484.4 & 23.98 & - & - & - & - & 29.10 \\
\hline
\end{tabular}




\section{VICTORIA BEJENARI and GABRIELA LISA}

Table 3

Kinetic parameters determined by the Freeman-Carroll method for stage II

\begin{tabular}{lccc}
\hline Sample code & $\mathrm{n}$ & $\mathrm{Ea}(\mathrm{kJ} / \mathrm{mol})$ & $\ln \mathrm{A}$ \\
\hline A & $0.83 \pm 0.008$ & $77.97 \pm 0.45$ & $11.30 \pm 0.10$ \\
SCG A & $1.45 \pm 0.002$ & $171.98 \pm 1.81$ & $30.80 \pm 0.39$ \\
L & $0.44 \pm 0.008$ & $122.80 \pm 1.56$ & $17.45 \pm 0.29$ \\
SCG L & $2.33 \pm 0.016$ & $164.85 \pm 1.17$ & $29.81 \pm 0.26$ \\
GB & $0.47 \pm 0.009$ & $118.17 \pm 1.70$ & $16.74 \pm 0.32$ \\
SCG GB & $1.85 \pm 0.001$ & $144.31 \pm 0.91$ & $25.44 \pm 0.20$ \\
P & $1.21 \pm 0.013$ & $103.72 \pm 0.85$ & $16.94 \pm 0.19$ \\
SCG P & $0.71 \pm 0.004$ & $156.35 \pm 0.43$ & $27.60 \pm 0.09$ \\
O & $1.02 \pm 0.017$ & $90.69 \pm 0.98$ & $14.00 \pm 0.22$ \\
SCG O & $2.11 \pm 0.009$ & $160.40 \pm 0.73$ & $28.88 \pm 0.16$ \\
M & $0.74 \pm 0.078$ & $103.66 \pm 0.88$ & $16.99 \pm 0.20$ \\
SCG M & $2.11 \pm 0.006$ & $167.30 \pm 0.49$ & $30.48 \pm 0.11$ \\
\hline
\end{tabular}

$\mathrm{n}=$ reaction order; $\mathrm{Ea}=$ apparent activation energy; $\mathrm{A}=$ pre-exponential factor

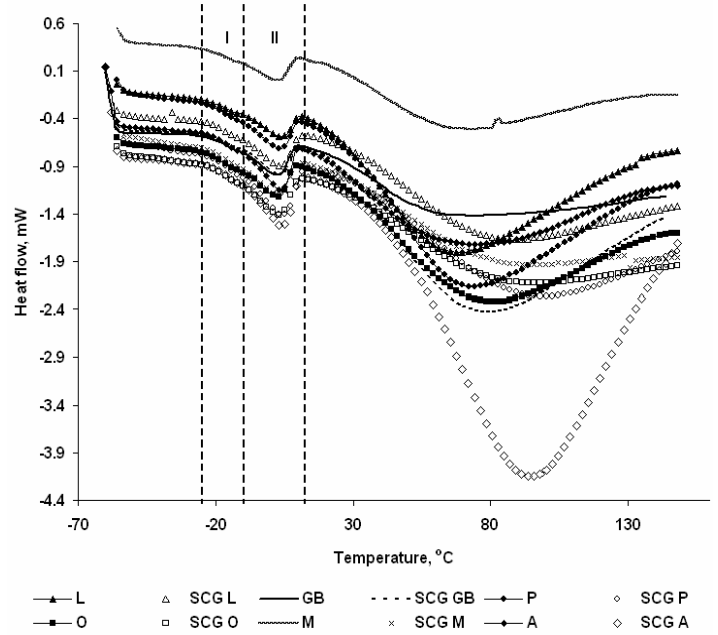

Figure 3: DSC curves of the first heating cycle for the six types of coffee and coffee grounds

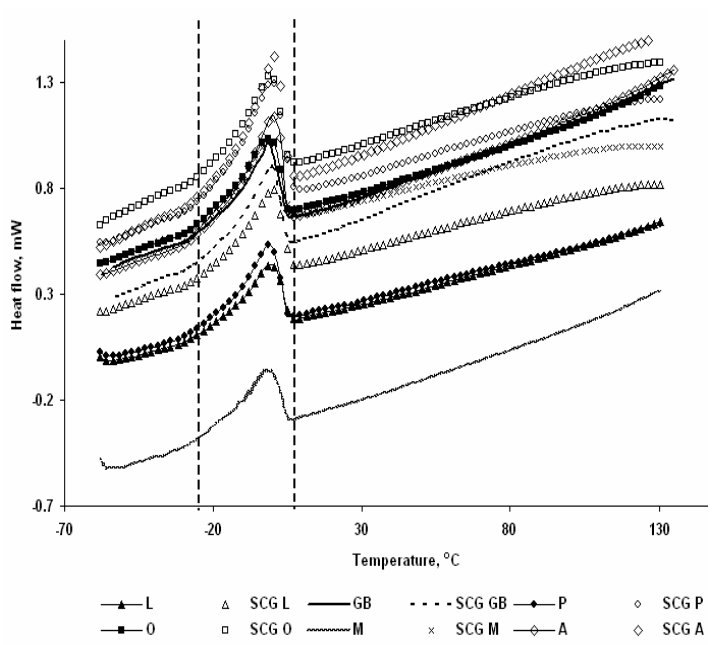

Figure 4: DSC curves of the cooling cycle for the six types of coffee and coffee grounds

Table 4

Melting peaks and total melting heat

\begin{tabular}{lccc}
\hline \multirow{2}{*}{ Sample code } & \multicolumn{2}{c}{$\mathrm{T}_{\mathrm{m}}\left({ }^{\circ} \mathrm{C}\right)$ melting } & \multirow{2}{*}{$\begin{array}{c}\Delta \mathrm{H} \text { melting } \\
(\mathrm{J} / \mathrm{g})\end{array}$} \\
\cline { 2 - 3 } & $\mathrm{I}$ & $\mathrm{II}$ & -7.18 \\
A & -13.53 & 3.63 & -8.76 \\
SCG A & -13.53 & 3.79 & -4.56 \\
L & -13.69 & 3.14 & -5.67 \\
SCG L & -14.02 & 3.63 & -5.21 \\
GB & -14.86 & 2.63 & -5.51 \\
SCG GB & -13.86 & 3.80 & -4.88 \\
P & -14.52 & 3.64 & -7.53 \\
SCG P & -13.37 & 4.46 & -4.77 \\
O & -14.03 & 2.13 & -5.33 \\
SCG O & -14.37 & 3.12 & -4.33 \\
M & -14.01 & 2.82 & -5.42 \\
SCG M & -13.53 & 2.79 & \\
\hline
\end{tabular}


Table 5

Crystallization peaks and total crystallization heat

\begin{tabular}{lcc}
\hline Sample code & $\begin{array}{c}\mathrm{T}_{\mathrm{m}}\left({ }^{\circ} \mathrm{C}\right) \\
\text { crystallization }\end{array}$ & $\begin{array}{c}\Delta \mathrm{H} \text { crystallization } \\
(\mathrm{J} / \mathrm{g})\end{array}$ \\
\hline A & 0.025 & 7.64 \\
SCG A & 0.360 & 9.11 \\
L & -0.99 & 5.14 \\
SCG L & 0.017 & 5.13 \\
GB & -1.64 & 5.34 \\
SCG GB & -0.31 & 6.16 \\
P & -1.32 & 3.62 \\
SCG P & -0.14 & 5.29 \\
O & -1.48 & 5.22 \\
SCG O & -0.8 & 5.62 \\
M & -1.14 & 5.23 \\
SCG M & -1.50 & 3.52 \\
\hline
\end{tabular}

\section{CONCLUSION}

Following the thermogravimetric analysis performed for different types of coffee and related coffee grounds, important information was obtained on their thermostability. Considering the initial temperature at which thermal degradation begins as a criterion of thermostability, we can note that there was an increase in the thermal stability of the coffee grounds, compared to that of the coffee type from which they originate. The best thermostability has been found for the coffee grounds (P) containing 35\% Arabica coffee and $65 \%$ Robusta coffee. Also, for this sample, at temperatures above $320{ }^{\circ} \mathrm{C}$, the degradation mechanism changes, as confirmed by the appearance of an additional degradation stage, compared to other samples. The increase in the thermal stability of the coffee grounds, compared to the different types of coffee they originate from, is also demonstrated by the increase in the activation energy calculated by the FreemanCarroll method.

Differential calorimetry studies have made it possible to highlight the presence of coffee oil in the coffee grounds obtained from different types of coffee, which suggests that coffee grounds can be exploited to extract coffee oil for potential application in skin care cosmetics.

\section{REFERENCES}

1 N. Haman, G. Ferrentino, S. Imperiale and M. Scampicchio, J. Therm. Anal. Calorim., 132, 1065 (2018), https://doi.org/10.1007/s10973-018-6995-3

2 B. Janissen and T. Huynh, Resour. Conserv. Recycl., $\quad \mathbf{1 2 8}, \quad 110 \quad$ (2018), https://doi.org/10.1016/j.resconrec.2017.10.001
3 N. S. Caetano, D. Caldeira, A. A. Martins and T. M. Mata, Waste Biomass Valoris., 8, 1981 (2017), https://doi.org/10.1007/s12649-016-9790-z

4 L. F. Ballesteros, J. A. Teixeira and S. I. Mussatto, Food Bioprocess Technol., 7, 3493 (2014), https://doi.org/10.1007/s11947-014-1349-z

5 A. E. Atabani, S. M. Mercimek, S. Arvindnarayan, S. Shobana, G. Kumar et al., J. Air Waste Manage., 68, 196 (2018), https://doi.org/10.1080/10962247.2017.1367738

6 V. M. Ovando-Medina, N. E. Davila-Guzman, N. V. Perez-Aguilar, H. Martinez-Gutierrez, I. D. Antonio-Carmona et al., Iran. Polym. J., 27, 171 (2018), https://doi.org/10.1007/s13726-018-0598-5

E. S. Freeman and B. Carroll, J. Phys. Chem., 62, 394 (1958), https://doi.org/10.1021/j150562a003

8 W. B. Gurnule and S. S. Butoliya, J. Appl. Polym. $\begin{array}{llll}\text { Sci., } & \mathbf{1 2 2}, & 2181 & \text { (2011), }\end{array}$ https://doi.org/10.1002/app.34309

9 L. F. Ballesteros, M. A. Cerqueira, J. A. Teixeira and S. I. Mussatto, Carbohyd. Polym., 127, 347 (2015), https://doi.org/10.1016/j.carbpol.2015.03.047

10 J. Fermoso and O. Mašek, J. Anal. Appl. Pyrol., 130, 358 https://doi.org/10.1016/j.jaap.2017.12.007

11 M. Brebu and C. Vasile, Cellulose Chem. Technol., 44, 353 (2010), http://www.cellulosechemtechnol.ro/pdf/CCT9(2010)/ P.353-363.pdf

12 D. Ciolacu, F. Ciolacu and V. I. Popa, Cellulose Chem. Technol., 45, $13 \quad$ (2011), http://www.cellulosechemtechnol.ro/pdf/CCT12(2011)/p.13-21.pdf

13 P. Rantuch and T. Chrebet, Cellulose Chem. Technol., $\quad 48, \quad 461 \quad$ (2014), http://www.cellulosechemtechnol.ro/pdf/CCT56(2014)/p.461-467.pdf

14 M. Kobelnilk, G. G. Fontanari, D. L. Cassimiro, C. A. Ribeiro and M. S. Crespi, J. Therm. Anal. Calorim., 
VICTORIA BEJENARI and GABRIELA LISA

115, 2045 (2014), https://doi.org/10.1007/s10973-013-

3150-z

15 S. Calligaris, M. Munari, G. Arrighetti and L.

Barba, Eur. J. Lipid Sci. Technol., 111, 1270 (2009),

https://doi.org/10.1002/ejlt.200900042 